\title{
Study of the Vibratory Behavior of the Bridge under the Passage of Mobile Loads Convoys: Comparative Study between Uni- dimensional and Three-dimensional Modeling
}

\author{
Meriem Ouchenane ${ }^{a^{*}}$ \\ ${ }^{a}$ Laboratory of Materials and Durability of Constructions, Civil Engineering Department, Faculty of Science of Technology, \\ Constantine1 University, Algeria. \\ Received 24 March 2018; Accepted 21 May 2018
}

\begin{abstract}
In order to understand the dynamic behavior of bridges under the passage of convoys of moving vehicles, it was necessary to start with the example of a single moving force, however, this study was deemed insufficient because the bridge is under several vehicle forces simultaneously. As a result, this study focuses on the vibration of bridges subjected to convoys of several mobile loads. Based on the analysis of the equation of motion that manage this behavior for the case of a simplysupported unamortized thin beam, subjected to convoys of one, two, and three forces at constant speed. In order to verify the solution obtained for a convoy of $n$ forces through the superposition of solutions of single force with a time offset, see the influence of the spacing ' $\mathrm{e}$ ' between the forces of the convoy on the dynamic amplification factor and compare the results of the analytical study with those derived from the real model established by the software Csi Bridge.
\end{abstract}

Keywords: Beams Vibration; Convoy of Moving Loads; Dynamic Amplification Factor; Analytical Model.

\section{Introduction}

Research on the dynamic response of bridges due to moving loads has received particular attention in recent years. As a result of this research's significance, this study centers on characterizing the structural function of moving loads and identifying the effects on bridges.

Fryba L. [9] modelled the bridge as a simple supported beam crossed by a moving load; the problem is solved by the Laplace transform. Biggs J. M. and Al. [2] carried out an experimental study of the rolling mass case on a simple supported beam. Finite elements have been used by Henchi K. [10] to model the structure in three-dimensions under the effect of mobile loads. Broquet C. [4] represents the modeling of three-dimensional bridges with finite elements in order to analyze the dynamic behavior of bearing slabs. Based on the research by Foda A. [8], the bridge is modelled by an Euler-Bernoulli beam subjected to a moving mass, the resolution is obtained by the Green functions. Mehri B. [13] presented a study based on Green's functions with elastic supports. Lee H. P. [5] based on the equilibrium equation in matrix form using the Hamilton Principle and the modal method for determining the transient response, taking into account the interaction between the vehicle and the bridge structure. Lecheheb M. [11] presents a study describing an analytical resolution of vibration eigen waves for a rail structure under the influence of a mobile source, the rail is modelled as an infinite Euler beam placed on elastic and periodic supports. In another work, Lecheheb M. [12] studies the dynamic behavior of the rail under inclined loads, the rail is modelled as a curved beam under lateral loads and solves the problem by the functions of Green. Sahnoun's I. [16] study considered the vibratory behavior of bridge decks under the effect of a mobile source, the structure of the deck has been modelled in 3D under the software SAP 2000 and

\footnotetext{
* Corresponding author: ouchenane_m@yahoo.fr
}

\section{doi) http://dx.doi.org/10.28991/cej-0309145}

$>$ This is an open access article under the CC-BY license (https://creativecommons.org/licenses/by/4.0/).

(C) Authors retain all copyrights. 
the numerical simulation is done under MATLAB. Feng D. [7] studies a new method proposed to simultaneously identify bridge structural parameters and vehicle dynamic axle loads of a vehicle-bridge interaction system from a limited number of response measurements. Augustine P. [1] presents a dynamic moving load identification using optimal sensor placement and model reduction, he presents the recovery of the dynamic moving loads through measurement of a structural response at a finite number of optimally-selected locations, the developed algorithms are successfully implemented using ANSYS APDL and MATLAB programming environment. Wang Y. [17] studies the dynamic interaction of a vehicle traveling on a simply supported beam. A simple quarter-car planar model of the vehicle is taken into account; the system of the quarter-car model is treated as a moving mass with a mass less harmonic force rolling on a simply supported beam and presents analytical and numerical methodologies to evaluate the vehicle-beam coupling effects when the vehicle moves under variable speed condition. Sadallah M. [15] presents a static and dynamic study of an isostatic bridge, the objective was to study the static and the dynamic bridge state, and make a comparison between the two cases, distinguishing the least favourable. Finally, Boua B. [3] presents a study concerning the determination of the deflection of a bridge deck under rolling loads.

Rolling loads on bridge decks cause deformations, and these deformations must remain in the elastic domain in order to allow the bridge to fulfil its role. For this purpose, determining the deformations of the deck on the bridge under rolling loads is imperative and must be obtained in real time.

In addition, several methods of bridge structure modeling are possible but their validity remains questionable since most, and more specifically, the uni-dimensional model, lack the ability to realistically represent a bridge using accurate parameters, these models consider applied loads on the bridge and combine them as the resultant load, disregarding the actual forces being applied on the bridge. The actual forces acting on the bridge are several moving loads, which can be subjected with a shift in the time, this time offset $\Delta \mathrm{t}$ corresponds to the distance offset 'a' between two loads.

As a result, we have dedicated this study to treat the behavior of bridges subjected by mobile load convoys through comparing the two types of uni-dimensional and three-dimensional modeling.

This work consists of evaluating the impact of the bridge's structural on the dynamic response, the bridge has been demonstrated by two models, the first is a three-dimensional produced in a CSi Bridge environment using shell elements whose resolution is concretized and based on the finite elements theory, this model best represents a real bridge structure.

The second model is a uni-dimensional beam model using the Euler-Bernoulli theory and solving the differential equation that governs the motion, it is an analytical approach, based on the method of modal superposition, and the overall solution is obtained by evaluating the generalized functions by the convolution integral.

\section{Analytical Approach of a Beam Behavior through by Convoys Mobile Loads}

The transverse vibration equation of a homogeneous unamortized beam, without shearing the effect and subjected by moving loads $\mathrm{F}(\mathrm{x}, \mathrm{t})$ rolling at a constant speed $\mathrm{V}[2]$ is given as:

$E I\left(\frac{\partial^{4} w}{\partial x^{4}}\right)+m_{l} \frac{\partial^{2} w}{\partial t^{2}}=F(x, t)$

Where: $\mathrm{E}$ is the Young modulus, $\mathrm{I}$ is the inertia moment, $\mathrm{W}$ is the displacement, $\mathrm{x}$ is the longitudinal position of the mobile load, $\mathrm{t}$ is the time, $\mathrm{ml}$ is the bridge mass (or beam) per meter and $\mathrm{F}$ is the excitatory force.

$F(x, t)=\sum_{k=1}^{n_{c}} \delta\left(x-\bar{x}_{k}\right) F_{k}(t)$

Or nc is the number of forces biasing the beam at time t, and $\delta\left(x-\bar{x}_{k}\right)$ represents the Dirac function at the position $x=\bar{x}_{k}, a$ is the spacing between $F_{k}$ and $F_{k+1}$.

If $\bar{x}_{k} \prec 0 \Rightarrow a=0$ or $\bar{x}_{k} \succ 0 \Rightarrow F_{k}(t) \neq 0, \mathrm{~L}$ is the total length of the beam.

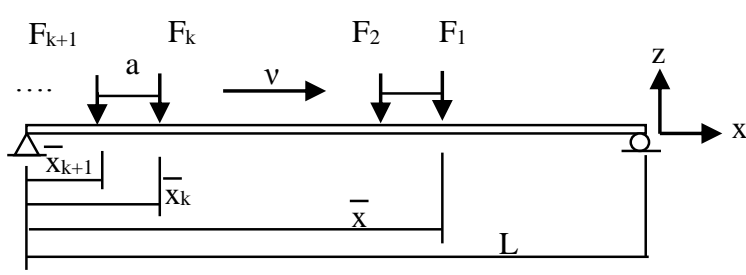

Figure 1. Beam under the effects of a mobile force convoy

In the same way as for a single moving force, using the modal representation, we have:

$w(x, t)=\sum_{j=1}^{\infty} \phi_{j}(x) y_{j}(t)$ 
Where: $\phi_{\mathrm{j}}$ is the own vector corresponds to the mode $n$ and $y_{j}(t)$ is the displacement of the mode $j$.

The modes orthogonality leads to [9]:

$\frac{\partial^{2} y_{j}}{\partial t^{2}}+\omega_{j}^{2} y_{j}=p_{j}(t), j=1,2, \ldots \ldots$

$\omega_{j}$ is the pulsation of mode $\mathrm{j}$ and $P_{j}(t)$ is the excitatory load of the mode $\mathrm{j}$.

With:

$$
p_{j}(t)=\int_{0}^{L} \phi_{j} F(\bar{x}, t) d x=\sum_{k=1}^{n_{c}} \phi_{j}\left(\bar{x}_{k}\right) F_{k}(t)
$$

The solution of Equation 4 for a single force is given by the Duhamel integral, for a convoy of $n_{c}$ mobile forces, the solution is obtained by superposition of the solutions of all the forces (for reasons of simplicity of writing we omits the $\mathrm{j}$ index of the modes, and we assume that the beam is initially at rest):

$y(t)=\sum_{k=1}^{n_{c}} y^{k}+\beta^{k}$

$y(t)$ is the forced response due to the force $\mathrm{k}$, is given by:

$\sum_{k=1}^{n_{c}} y^{k}=\sum_{k=1}^{n_{c}} \frac{1}{\omega} \int_{0}^{t_{k}} F_{k}\left(t_{k}\right) \phi\left(\bar{x}_{k}\right) \sin \left(\omega\left(t_{k}-\tau\right)\right) d \tau$ with: $0 \leq \bar{x}_{k}=\bar{x}_{1}-\sum_{l=1}^{k-1} a_{l} \leq L$

$\beta^{k}$ Represent the response of free vibrations due to the force $\mathrm{k}$, given by:

$\sum_{k=1}^{n_{c}} \beta^{k}=\sum_{k=1}^{n_{c}} y\left(\tau_{k}\right) \cos \omega\left(t_{k}-\tau_{k}\right)+\frac{\dot{y}\left(\tau_{k}\right)}{\omega_{d}} \sin \omega\left(t_{k}-\tau_{k}\right)$ with: $\tau_{k}=\left(\sum_{l=1}^{k} a_{l-1}+L\right) / v$ and $\bar{x}_{k}=\bar{x}_{1}-\sum_{l=1}^{k-1} a_{l} \geq L$

Where: $\tau$ is the time of one impulsion between two loads and $L$ is the total length of the beam.

\section{CSI Bridge Model}

The road bridge that we model is a two-span bridge, with a total length of $\mathrm{L}=26.625 \mathrm{~m}$, whose deck is in multiple beams ( 7 main beams), the slab has a straight width of $10.22 \mathrm{~m}$ and a thickness of $0.20 \mathrm{~m}$, the roadway consists in two traffic lanes which has a width of $3.5 \mathrm{~m}$, the supports consist in two abutments and a stack Figure 2 and 3.

Where:

$\mathrm{C} 1=0.175 \mathrm{~m}, \mathrm{C} 2=0.50 \mathrm{~m}$, and $\mathrm{C} 3=1.537 \mathrm{~m}$ which gives the total width $\mathrm{C}=10.22 \mathrm{~m} . \mathrm{B} 1=1 \mathrm{~m}, \mathrm{~B} 2=0.55 \mathrm{~m}, \mathrm{~B}=0.22 \mathrm{~m}$, B4=0.15 m, D1=1.3 m, D2=0.11 m, D3=0.033 m, D4=0.1 m, D5=0.25 $\mathrm{m}$ and D6=0.25 m.

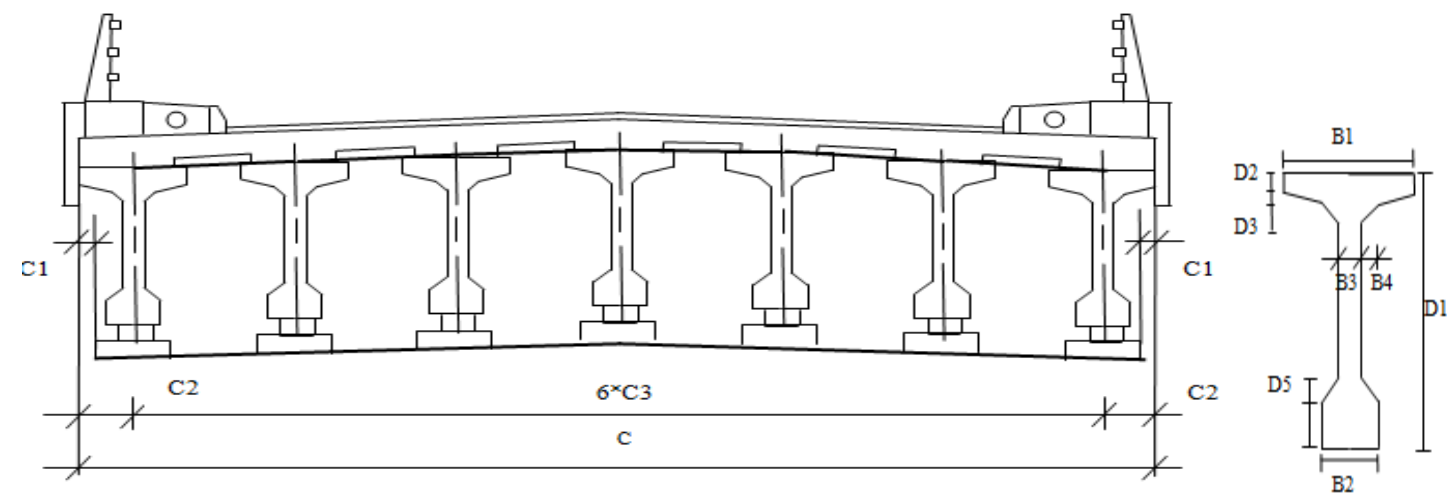

Figure 2. Beam Detail of the Deck

Figure 3. Cross Section of the Deck

The software CSI bridge SAP v15 is a structural calculation software, particularly adapted to engineering structures that allows the calculation of internal forces in a structure; it uses the finite elements principle, the analysis method modeling is a step-by-step type process based on the analysis time (Time History Analysis), where we seek the solution of the equilibrium equation in each step increment. We use this type of analysis if we are interested in dynamic response, the number of vehicles can be run simultaneously on the track, each with its own start time, position, direction, and speed. Restrictions imposed by this software on the choice of the mesh as well as its refinement are a fine analysis wanted by the designer. CSI bridge takes dynamic loads without a coefficient of increase because it allows us to give the real loading systems. 


\section{Case Study}

In this example, we present the dynamic amplification factor 'DAF' for a beam under a convoy of two moving forces.

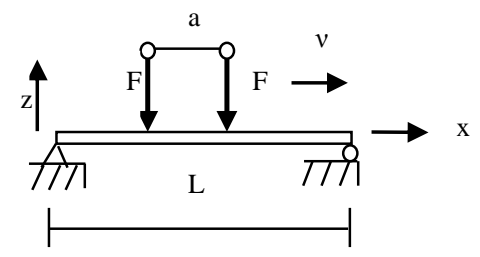

Figure4. Simple supported beam subjected to convoy of mobile loads

The transition from the real model (bridge deck in two dimensions) to the uni-dimensional beam model is done by calculating the arrow at the center of the beam which is a function of these geometric characteristics and the load, and equating it to the arrow in the bridge middle from Csi Bridge Software.

Beam and load data:

$\mathrm{m}_{\mathrm{l}}=4.46 \times 10^{2} \mathrm{~kg} / \mathrm{m}$ which is the density per unit of length, $\mathrm{E}=36 \times 10^{9} \mathrm{~N} / \mathrm{m}$ is the young modulus, $\mathrm{b}=0.8 \mathrm{~m}$ and $\mathrm{h}=2.23$ $\mathrm{m}$ are the beam dimensions, $\mathrm{A}=1.784 \mathrm{~m}^{2}$ is the beam section, $\mathrm{I}=0.7393 \mathrm{~m}^{4}$ is the inertia, $\mathrm{L}=26.625 \mathrm{~m}$ is the beam length, $\mathrm{g}=9.81 \mathrm{~m} / \mathrm{s}^{2}, \mathrm{v}=10 \mathrm{~m} / \mathrm{s}$ is the speed of the loads of the convoy, $\mathrm{F} 1=\mathrm{F} 2=-300 \times 10^{3} \mathrm{~N}$ which are the first, and the second load of the convoy.

Physical description:

The analytical pulsation is given by: $\omega_{j}=(j \pi)^{2} \sqrt{\frac{E I}{m_{l} L^{4}}}$

The analytical solution of displacement w (for a single moving force) is [6]:

$W_{j}(X, t)=\frac{2 F}{m_{l} L} \frac{1}{\left(\omega_{j}^{2}-\Omega_{j}^{2}\right)}\left(\sin \left(\Omega_{j} t\right)-\left(\frac{\Omega_{j}}{\omega_{j}}\right) \sin \left(\omega_{j} t\right)\right) \sin \frac{j \pi x}{L}$

With: $\Omega_{\mathrm{j}}=\frac{j \pi v}{L}$ and: $0 \leq t \leq \frac{L}{v}$

$w_{j}(x, t)=\sum_{j=1}^{\infty} \sqrt{\frac{2}{m_{l} L}} \cdot\left(y_{j}(\tau) \cos \left(\omega_{j}(t-\tau)\right)+\frac{\dot{y}_{j}(\tau)}{\omega_{j d}} \sin \left(\omega_{j}(t-\tau)\right)\right) \cdot \sin \frac{j \pi x}{L}, t \geq \tau=\frac{L}{v}$

The beam is considered initially at rest.

The passage speed of the convoy loads used in the example is $\mathrm{V}=10 \mathrm{~m} / \mathrm{s}$.

The computation principle for the dynamic response is the superposition of the solutions of a single force with a time offset to obtain the solution of a convoy of $\mathrm{n}$ forces.

\section{Results and Discussions}

\subsection{Analytical Results}

This section presents the uni-dimensional model of the bridge illustrated analytically as a beam and introduces the example studied in the Matlab Calculation Software to get the desired results of this study (from Figure 5 to 10).

\subsubsection{Effect of the Spacing between the Convoy Loads on the Bridge Behavior}

Figure 5 represents the displacements for the convoy of two loads for the different cases of spacing between the convoy loads, it represents the symmetry with respect to the points of the maximum displacement and we notice that increasing the spacing between the convoy loads causes a decrease in the corresponding displacements as shown in Figure 5. This means that the minimum spacing between the convoy loads gives a maximum displacement. 


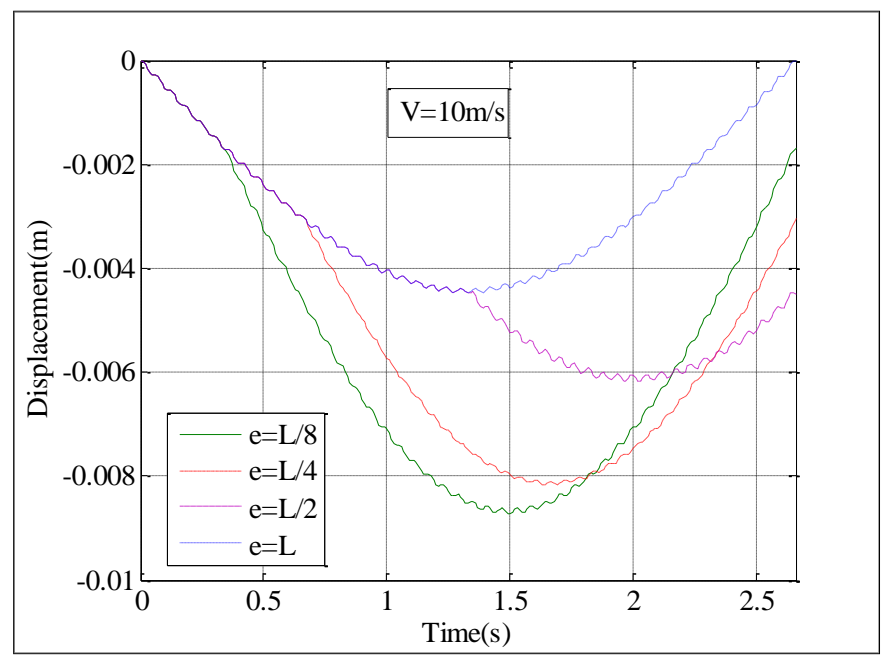

Figure 5. Displacement of the beam for the case of a convoy of two loads for different spacing e=L/8, e=L/4, e=L/2, e=L for a speed $V=10 \mathrm{~m} / \mathrm{s}$

Table 1. Maximum displacement for different spacing between the two loads of the convoy for $\mathrm{V}=10 \mathrm{~m} / \mathrm{s}$

\begin{tabular}{ccccc}
\hline & $\mathbf{e}=\mathbf{L} / \mathbf{8}$ & $\mathbf{e}=\mathbf{L} / \mathbf{4}$ & $\mathbf{e}=\mathbf{L} / \mathbf{2}$ & $\mathbf{e = L}$ \\
\hline The maximum displacement $(\mathrm{m})$ & 0.008727 & 0.008159 & 0.006175 & 0.004479 \\
Time $(\mathrm{s})$ & 1.5 & 1.69 & 2.03 & 1.33 \\
\hline
\end{tabular}

We note that the displacement increases while decreasing the spacing between the convoy loads (Table 1 and Figure 5), this amplification increases by $37.87 \%$ for the case of $\mathrm{e}=\mathrm{L} / 2$ compared to that of $\mathrm{e}=\mathrm{L}$ (which is identical to the case of a single charge).

For the case where e=L/4, the amplification is increasing by $32.13 \%$ compared to that of e=L/2 and $82.16 \%$ more amplified with respect to $\mathrm{e}=\mathrm{L}$.

For the case where e=L/8, the amplification is increasing by $3.96 \%$ compared to that of e=L/4, is $41.33 \%$ more amplified with respect to that where $\mathrm{e}=\mathrm{L} / 2$, and finally amplified by $94.84 \%$ compared to that of $\mathrm{e}=\mathrm{L}$.

5.1.2. Effect of the Spacing Between the Convoy Loads on the Dynamic Amplification Factor 'DAF'

The convoy consists of three loads with $\mathrm{V}=10 \mathrm{~m} / \mathrm{s}$.

$U_{\text {sta }}=(F 1+F 2+F 3) * L^{4} /(48 * E * I)$

$U_{\text {sta }}$ is the static arrow and $\mathrm{DAF}=\mathrm{U}_{\mathrm{dyn}} / \mathrm{U}_{\text {sta }}[4]$.

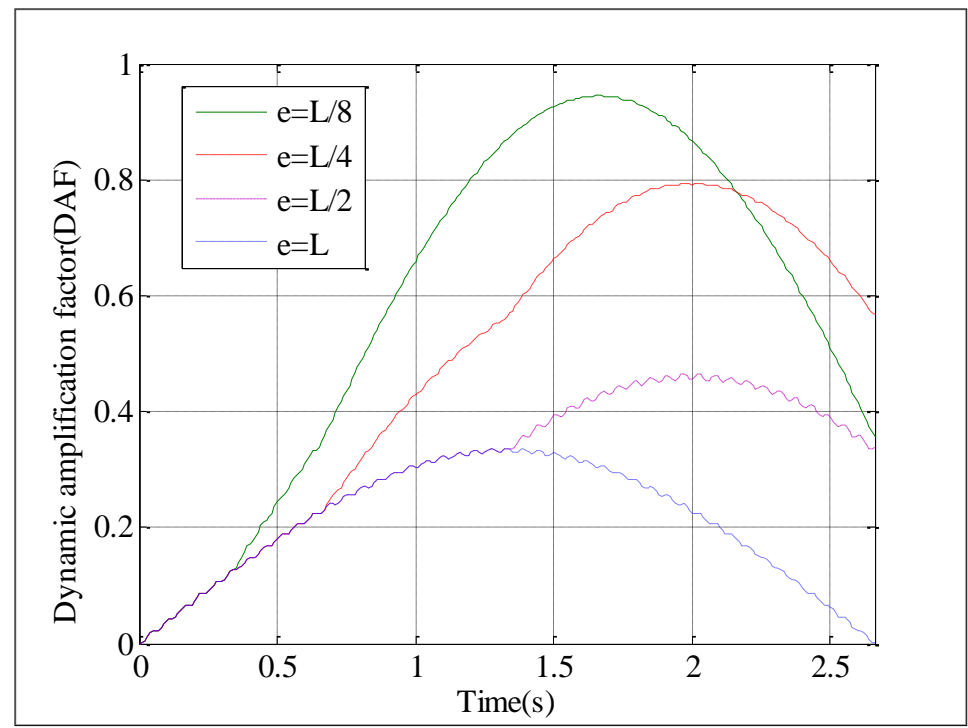

Figure 6. Dynamic amplification factor along the beam for the case of a three loads in the convoy for different spacing $e=L / 8, e=L / 4, e=L / 2, e=L$ and for $V=10 \mathrm{~m} / \mathrm{s}$ 


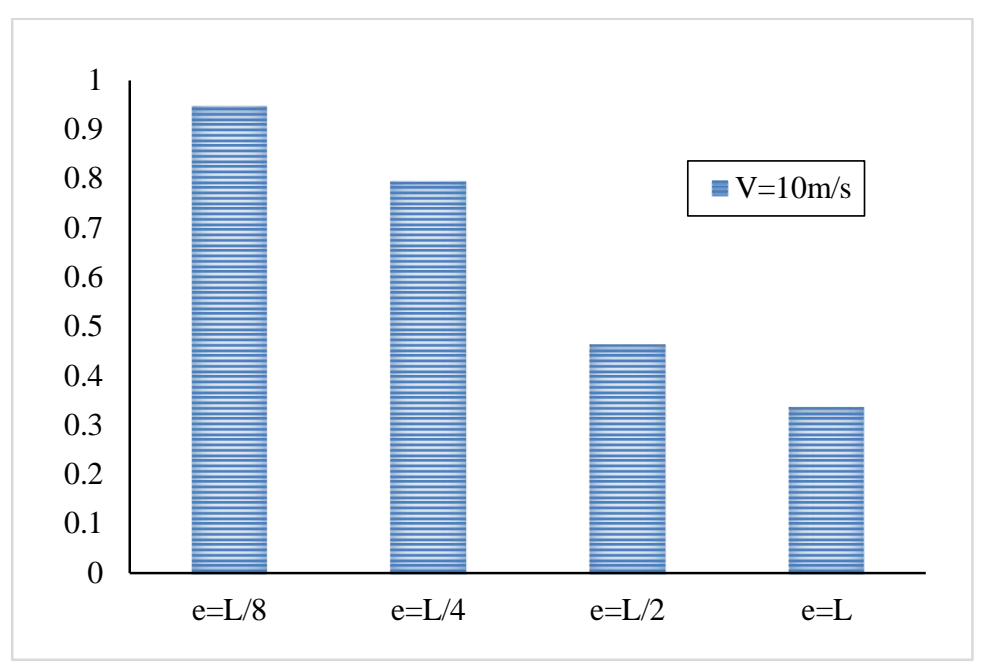

Figure 7. Maximum dynamic amplification factor for different spacing between the three loads of the convoy for $V=10 \mathrm{~m} / \mathrm{s}$

Table 2. Maximum dynamic amplification factor for different spacing between the three loads of the convoy for $V=10 \mathrm{~m} / \mathrm{s}$

\begin{tabular}{ccccc}
\hline & $\mathbf{e}=\mathbf{L} / \mathbf{8}$ & $\mathbf{e}=\mathbf{L} / \mathbf{4}$ & $\mathbf{e}=\mathbf{L} / \mathbf{2}$ & $\mathbf{e = L}$ \\
\hline DAF (max) & 0.9456 & 0.7945 & 0.4648 & 0.3368 \\
Time (s) & 1.66 & 2 & 2 & 1.33 \\
\hline
\end{tabular}

We note that the dynamic amplification increases in decreasing the spacing between the convoy loads (Table 2 and Figure 7), this amplification increases by $38 \%$ for the case of $\mathrm{e}=\mathrm{L} / 2$ compared to that of $\mathrm{e}=\mathrm{L}$ (which is identical to the case of a single charge).

For the case where $\mathrm{e}=\mathrm{L} / 4$, the amplification is increasing by $70.9 \%$ compared to that of $\mathrm{e}=\mathrm{L} / 2$ and $135.9 \%$ more amplified with respect to $\mathrm{e}=\mathrm{L}$.

For the case where $\mathrm{e}=\mathrm{L} / 8$, the amplification is increasing by $19 \%$ compared to that of $\mathrm{e}=\mathrm{L} / 4$, is $103.44 \%$ more amplified with respect to that where $\mathrm{e}=\mathrm{L} / 2$ and finally amplified by $180.76 \%$ compared to that of $\mathrm{e}=\mathrm{L}$.

\subsubsection{Effect of the Number of Loads in the Convoy on the Dynamic Amplification Factor 'DAF'}

Figures 8 and 9 present the displacements and the dynamic amplification factor for the three types of convoys of one, two and three loads for the case of a fixed spacing between the loads e=L/4 and for a speed of $\mathrm{V}=10 \mathrm{~m} / \mathrm{s}$.

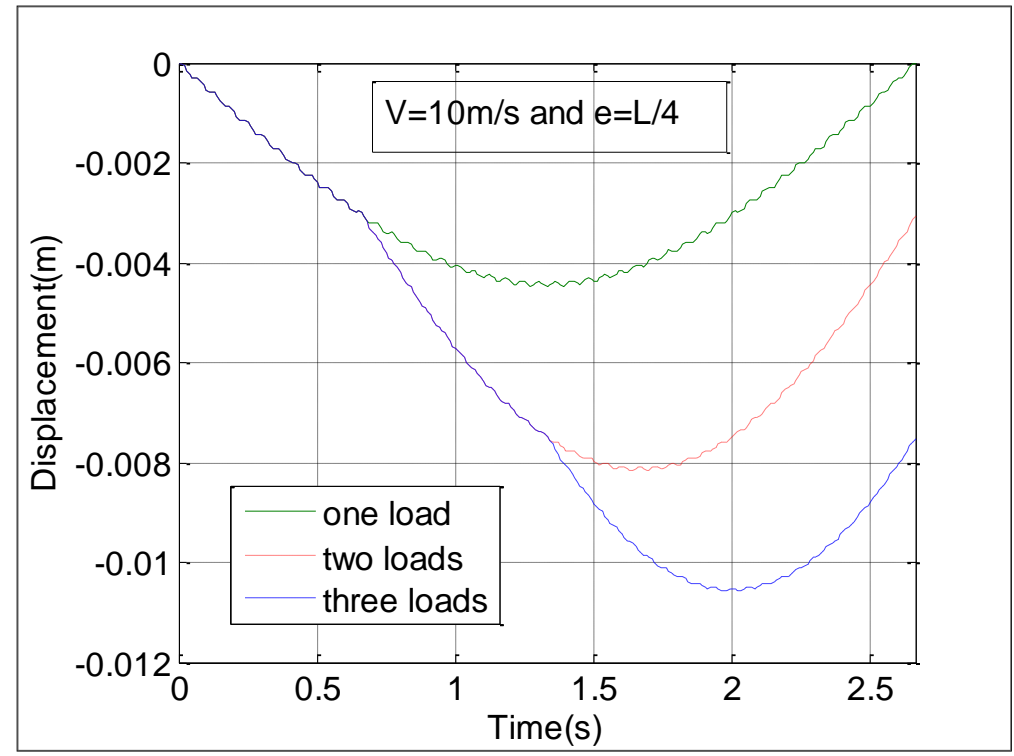

Figure 8. Maximum displacement of the beam for different convoy cases of one, two and three loads spaced by e=L/4 for $\mathrm{V}=\mathbf{1 0} \mathrm{m} / \mathrm{s}$ 


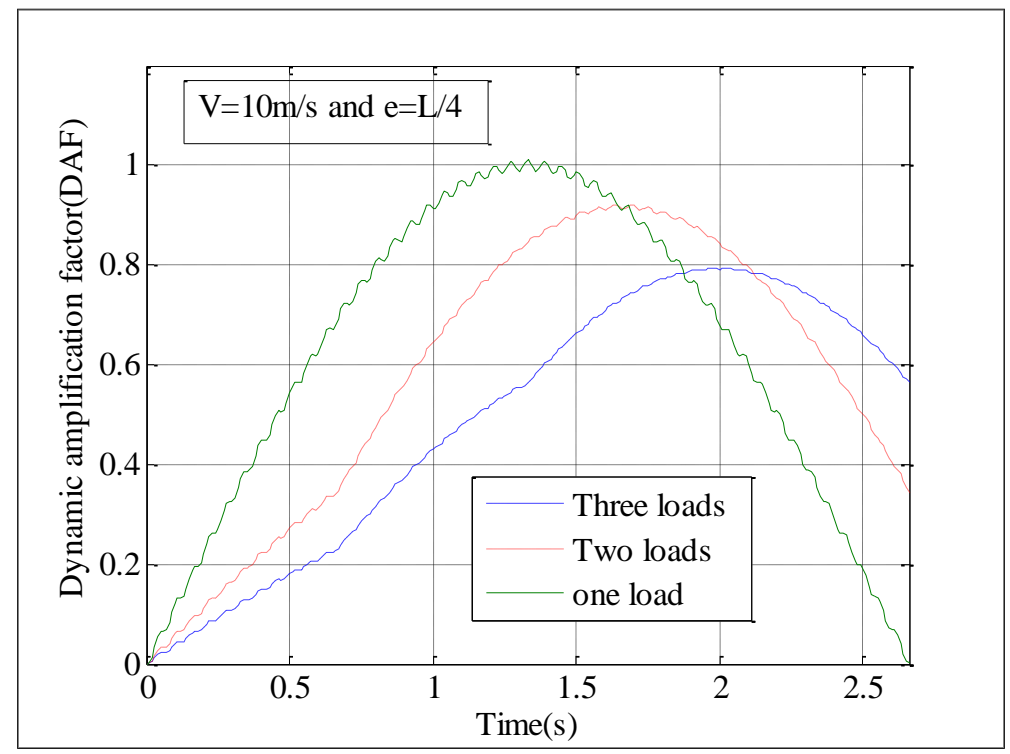

Figure 9. Dynamic amplification factor for different convoy of one, two and three loads by $e=L / 4$ for $V=10 \mathrm{~m} / \mathrm{s}$

Table 3. Maximum dynamic amplification factor for different convoy of one, two and three loads for $\mathrm{V}=10 \mathrm{~m} / \mathrm{s}$

\begin{tabular}{cccc}
\hline & One load & Two loads & Three loads \\
\hline $\mathrm{U}_{\mathrm{dyn}}(\mathrm{m})$ & -0.004479 & -0.008159 & -0.01059 \\
$\mathrm{U}_{\mathrm{sta}}(\mathrm{m})$ & -0.0044 & -0.0089 & -0.0133 \\
$\mathrm{DAF}$ & 1.018 & 0.9167 & 0.794 \\
Time $(\mathrm{s})$ & 1.33 & 1.69 & 1.97 \\
\hline
\end{tabular}

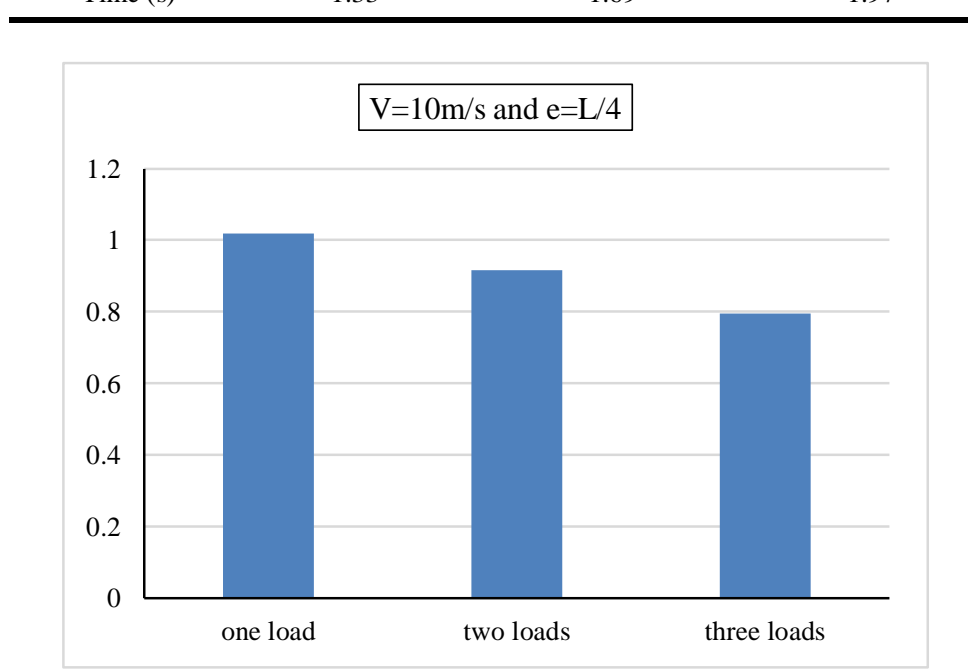

Figure 10. Maximum dynamic amplification factor for different convoy cases of one, two and three loads for $\mathrm{V}=10 \mathrm{~m} / \mathrm{s}$

Figure 8 shows that each time the number of loads in the convoy increases, it directly induces an increase of the displacement, but only if the spacing between the convoy loads applied loads simultaneously on the bridge, resulting in maximum displacement. The contrary occurs with respect the dynamic amplification, which means that the dynamic amplification factor decreases by increasing the number of charges in the convoy as shown in Figure 9 and 10.

We note that the dynamic amplification decreases in increasing the number of loads in the convoy (Table 3 , Figure 9 and 10); the displacement increases by $82.16 \%$ but the amplification decreases by $9.95 \%$ for the case of two loads in the convoy compared to that of one load in the convoy (which is identical to the case of a single load).

For the case where we have three loads in the convoy, the displacement increases by $29.80 \%$ but the amplification decreases by $13.39 \%$ compared to that when we have two loads in the convoy, also the displacement increases by $136.44 \%$ and the amplification decreases by $22 \%$ with respect to one load. 
This decrease in the dynamic amplification is justified because a single mobile load on the bridge causes a punching effect on the deck, whereas increasing the number of loads in the convoy causes a decrease in this punching effect despite the increase in the value of the resulting load of the deck.

\subsection{Real Model by CSI Bridge}

The figures that we present (Figure 11, 12 and 13) are produced using Microsoft Excel. They present the results from the bridge structure calculation software CSI bridge that portrays the real modeling of the bridge structure in three dimensions.

5.2.1. Convoy of two Loads with $V=10 \mathrm{~m} / \mathrm{s}$

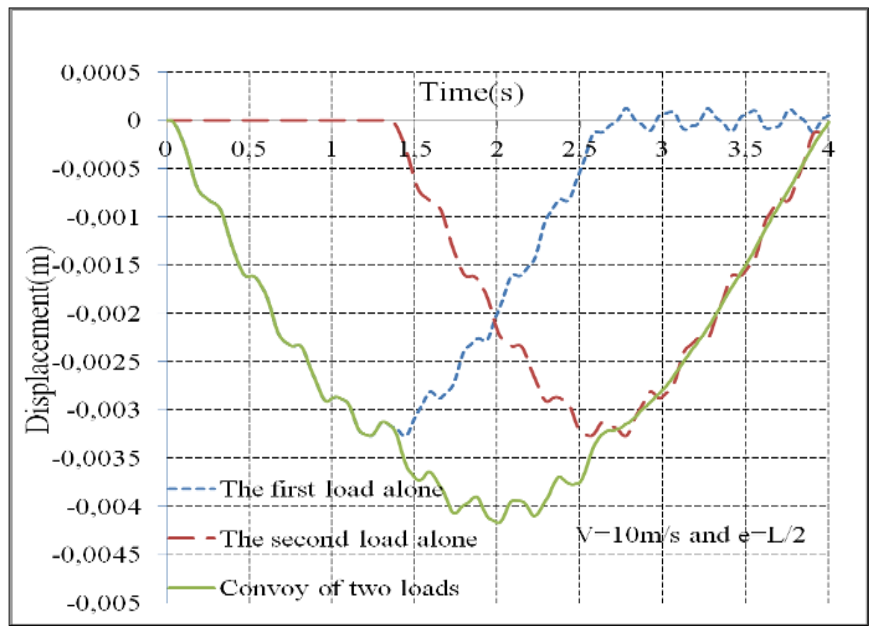

Figure 11. Displacement of the bridge for a spacing between the two forces of the convoy $e=L / 2$ and for $V=10 \mathrm{~m} / \mathrm{s}$

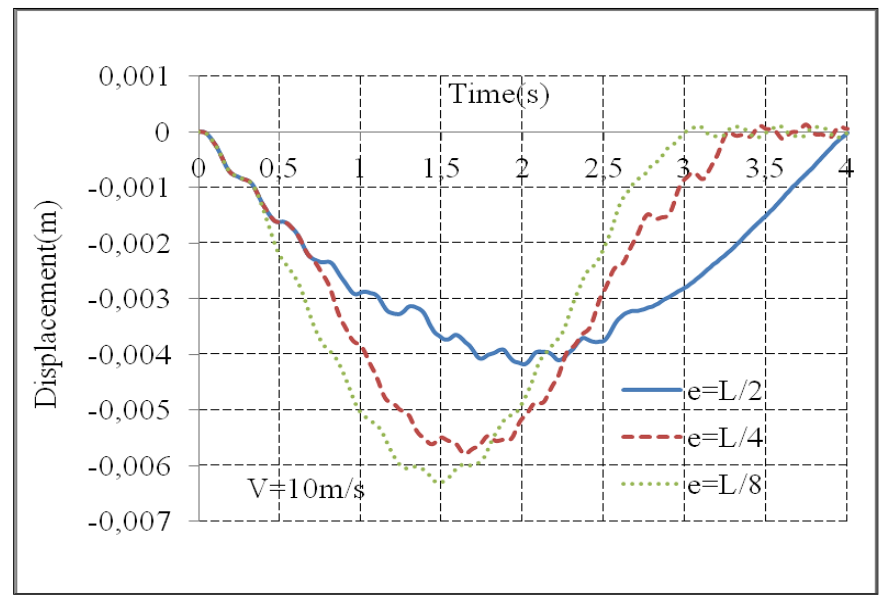

Figure 12. Displacement of the bridge for a spacing between the two loads of the convoy $e=L / 2, e=L / 4$ and $e=L / 8$ and for $\mathrm{V}=\mathbf{1 0} \mathrm{m} / \mathrm{s}$

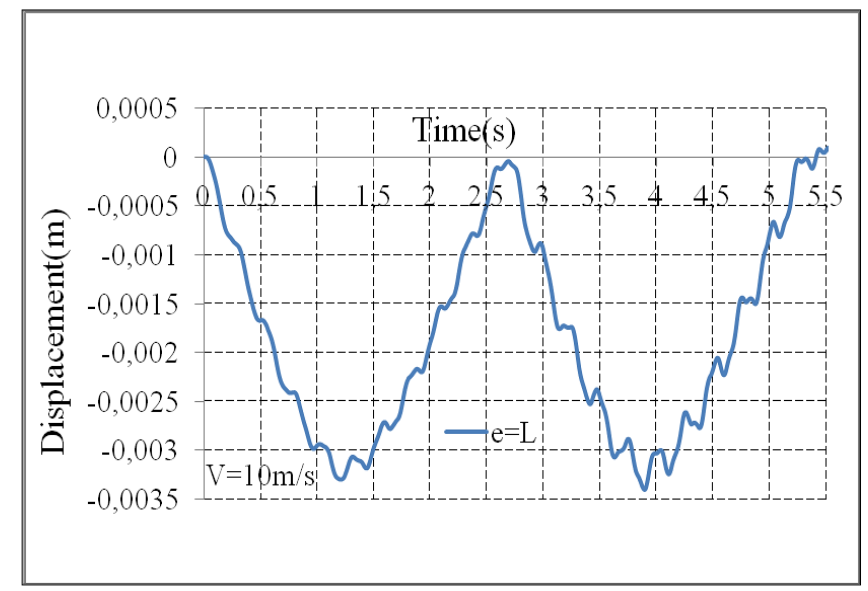

Figure 13. Displacement of the bridge for a spacing between the two loads of the convoy e=L and for $V=10 \mathrm{~m} / \mathrm{s}$ 
The computation of displacements on a bridge during the passage of a load convoy is done by the superposition of the displacements induced by each load of the convoy separately, with respecting the time of entry of each load on the bridge, and this is explained in Figure 11. The displacement induced by the first load of the convoy entering the bridge at the time $\mathrm{t}=0 \mathrm{~s}$ is depicted in blue; in red we present the displacement of the bridge under the passage of one load also but only after a time $t=1.33 \mathrm{~s}$ which correspond to a distance of $\mathrm{L} / 2$. By superimposing the two displacements, we obtain the maximum displacement of the bridge under the effect of passage of a convoy of two loads spaced by e=L/4, shown in Figure 12.

By analyzing the results and referring to Figure 12 (the loads of the convoy occurs at the same time on the bridge), we notice the same remarks regarding displacement, which means that increasing spacing between loads of the convoy increases the displacement.

Concerning the spacing $\mathrm{e}=\mathrm{L}$ between the loads of the convoy for the case of two loads (Figure 13), this behavior is identical to that of one load but repeat with an time of passage equal to the double of that necessary for the passage of a single load this means that $\mathrm{t}=2 \mathrm{~T}$ with $\mathrm{T}=\mathrm{L} / \mathrm{V}$, and at the exit of the first load, the second load of the convoy is also still on the bridge.

\subsection{Comparison of Analytical Results with Those of CSI Bridge}

Figure 14 shows a comparison between the two types of models studied: a real modeling established by the software CSI bridge and a beam model which is the analytical model, for a constant speed and for the case of convoys of two forces spaced by L/2, this figure is established by introducing the results from the CSI bridge software for the threedimensional model and the Matlab software for the case of the analytical model of the uni-dimensional beam using Microsoft Excel to be able to compare them, we see that the results from the Csi Bridge and analytics are similar and satisfactory for the case of a convoy of two loads and that of the entire length of the bridge.

Entered of the second load of the convoy

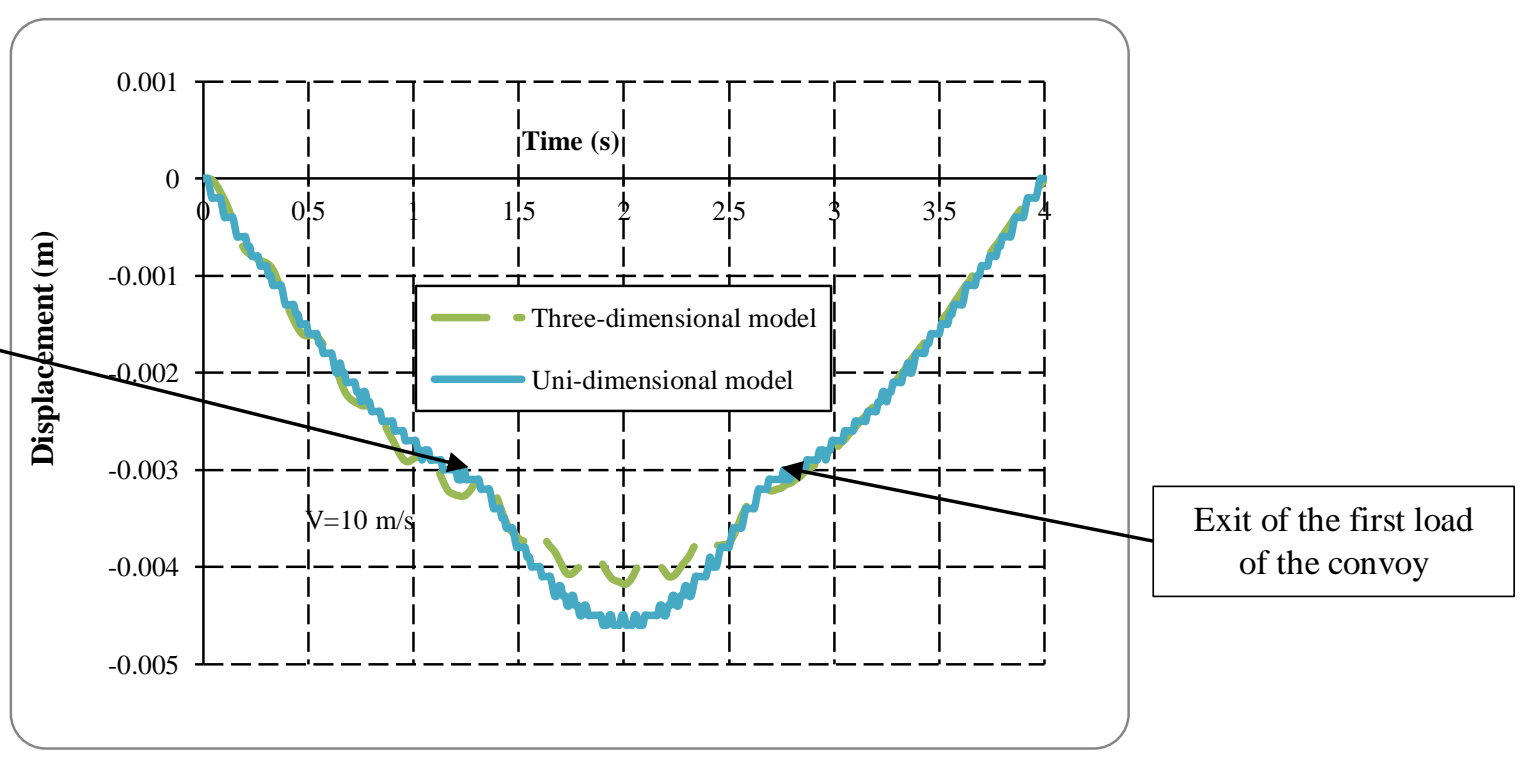

Figure 14. Comparison of the Analytical results with those of the Csi Bridge for the case of a convoy of two forces spaced by $e=L / 2$ for $V=10 \mathrm{~m} / \mathrm{s}$

Regarding the dynamic amplification factor for varying speeds between 10 to $170 \mathrm{~m} / \mathrm{s}$ (Figure 15), a consistency of almost $100 \%$ between the two methods is observed and that for speeds vary from $80 \mathrm{~m} / \mathrm{s}$ to $110 \mathrm{~m} / \mathrm{s}$, which are average speeds. 


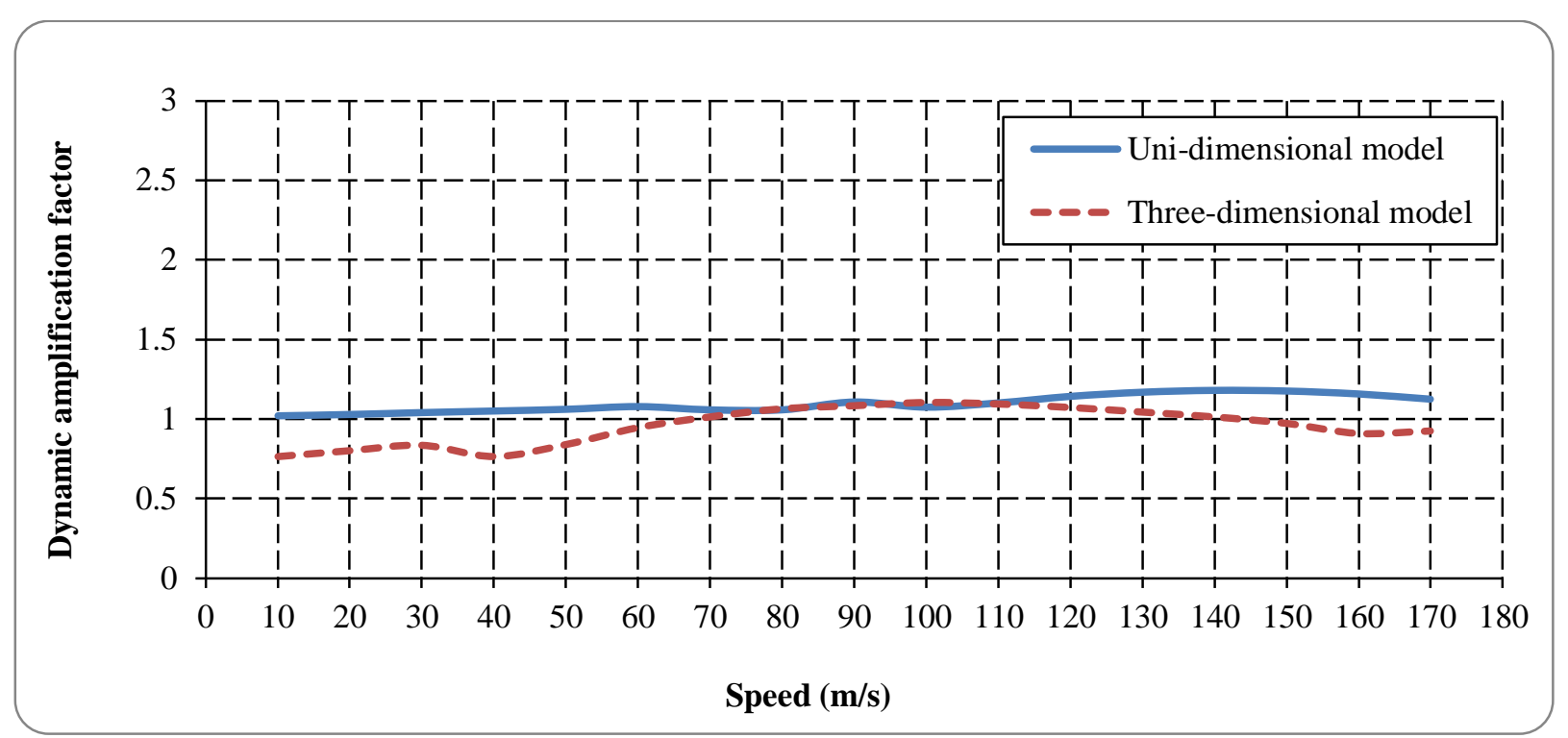

Figure 15. Dynamic amplification factor for the Analytical and the Csi Bridge models for the case of a convoy of two loads with $\mathrm{e}=\mathrm{L} / 2$

\section{Conclusion}

Based on the analysis obtained, it can be concluded that displacement on the bridge increases with increasing the number of loads in the convoy because the resultant from all forces applied simultaneously cause movement on the bridge which directly results in displacement. While the dynamic amplification decreases with increasing number of loads of the convoy. This decrease in dynamic amplification is explained through the concept of the punching effect due to a single mobile load on the bridge on the deck.

Also increasing the number of loads in the convoy causes a decrease in this punching effect, despite the increase in the value of the resulting load, which is twice for a convoy of two loads and the triple for a convoy of three loads comparing it with the value of a convoy of a single load, which also justifies the increase of the corresponding displacement.

The comparison of the analytical results with those of Csi Bridge for the case of a convoy of forces shows that the results of the two types of models by Csi Bridge or analytical method are very satisfactory. Despite this, we notice a certain imbalance just at the moment of the entry of the second load on the bridge and it lasts until the exit of the first charge where the behavior coincides outside this interval with the analytical results. This is explicable because the real model takes into consideration other effects such as the adhesion forces with the roadway and that for the different loads of the convoys. Despite disregarding some aspects of the analytical model, the study encompassed a well-rounded comparison of uni-dimensional modeling and three-dimensional modeling of mobile load convoys on a bridge.

Regarding the dynamic amplification factor for medium speeds, neglected parameters for the uni-dimensional model do not influence the results, and the dynamic amplification of structure is almost identical for the two types of studied models.

\section{References}

[1] Augustine P. Dynamic moving load identification using optimal sensor placement and model reduction. Theses and Dissertations. Paper 971. (2015).

[2] Biggs, J. L. Introduction to structural Dynamics. McGraw Hill, New York, (1964).

[3] Boua B. Détermination de la déflexion d'un tablier de pont dalle sous charge roulante. Nature and technologie. A- Sciences fondamentales et Engineering, $n^{\circ}$ 08/Janvier. Pages 41 to 49 (2012).

[4] Brockuet C. Comportement Dynamique des Dalles de Roulement des Ponts en béton Sollicités par le trafic Routier, École polytechnique fédérale de Lausanne (EPFL) EPFL (1999).

[5] Chang, D. and Lee, H. Impact Factors for Simple-Span Highway Girder Bridges. J. of Structural Eng. (ASCE). Vol 120, N³, (1994). pp 704-715.

[6] Clough, R. W. and Penzien, J. Dynamic of Structures. McGraw Hill, New York. (1993).

[7] Feng D. Simultaneous identification of bridge structural parameters and vehicle loads. Journal of computers and structures, Elsevier. 157 pages 76-88. (2015).

[8] Foda A. and Abudjabbar Z. A dynamic green function formulation for the response of a beam structure to moving mass. Journal 
of sound and vibration. pp 295-306, 210(3), 1998.

[9] Fryba, L. Vibration of Solids and Structures under Moving Loads. Noordhoff Intenational Publishing, Groningen, the Netherlands. (1972).

[10] Henchi K. Analyse dynamique des ponts par éléments finis sous la sollicitation des véhicules mobiles, Université de Compiègne, Compiègne, France, 243 pages 1995.

[11] Lecheheb M. Réponse dynamique d'une structure rail sur appuis continus sous l'effet d'une source mobile par superposition des ondes de Bloch. Journal of Advanced Research in Science and Technology ISSN: 2352-9989. (2018).

[12] Lecheheb M. Green Function of Curved Rail-Beam. Journal of materials and engineering structures. Vol: 4. pages 235-244. (2017).

[13] Mehri B. And all. Dynamique green function solution of beams under a moving loads with different boundary conditions. Transaction B: Mechanical Enbineering, Vol. 16, No. 3, pp. 273-279. 2009.

[14] Ouchenane M. Advanced Materials Research, Trans Tech Publications, Switzerland, doi:10.4028/www.scientific.net/AMR.324.396. pp 396-399 Vol. 324. 2011.

[15] Sadallah M. Etude statique et dynamique d'un pont isostatique de l'échangeur sur l'intersection de la RN22 avec la RN35. Thesis Presented for the Diploma of Magister in Civil Engineering Option: Basic Infrastructure and Geotechnical-Public Works. University of Abou bekr Belkaid Tlemcen, Faculty of technology, Civil Engineering Department, Algeria.114 pages. (2013).

[16] Sahnoun I. Comportement vibratoire des structures ponts saines et altérées sous charges mobiles. Thesis Presented for the Diploma of Magister in Civil Engineering, University of the Brothers Mentouri Constantine, Faculty of Science and Technology, Civil Engineering Department, Algeria.103 pages. (2015).

[17] Wang Yi-Ming. The interaction dynamics of a vehicle traveling along a simply supported beam under variable velocity condition. Acta Mech 225, 3601-3616, DOI 10.1007/s00707-014-1163-8, springer. (2014). 